\title{
Too Big Too Fast? Potential Implications of the Rapid Increase in Emergency Medicine Residency Positions
}

\author{
Mary R. C. Haas, MD, Laura R. Hopson, MD, and Brian J. Zink, MD
}

\begin{abstract}
Emergency medicine (EM) has expanded rapidly since its inception in 1979. Workforce projections from current data demonstrate a rapid rise in the number of accredited EM residency programs and trainee positions. Based on these trends, the specialty may soon reach a point of saturation, particularly in urban areas. This could negatively impact future trainees entering the job market as well as the career plans of medical students. More time and resources should be devoted to obtaining accurate projections, assessing the distribution of emergency physicians in rural versus urban settings, and implementing central workforce planning to protect the future of graduating trainees.
\end{abstract}

$\mathrm{E}^{\mathrm{n}}$ mergency medicine (EM) has been undergoing a rapid expansion in the number of residency training spots. The long-term implications are unclear, raising several questions: Is EM growing too big, too fast? What happens when the number of annual residency graduates exceeds the number of available job positions? Will the rapid increase in residency programs harm trainees aiming to secure a position postresidency in what may become a saturated job market? Will concerns about the job market affect medical student specialty selection? What are the implications for the specialty should such a mismatch of supply and demand occur? The intent of this paper is to raise awareness of potential challenges for EM as it completes its evolution into a mature specialty.

\section{BACKGROUND}

An understanding of the historical development of EM helps to illuminate the current state of training in the field. EM emerged in the 1960s, after the need for specialized emergency care was finally recognized in the post-World War II era. ${ }^{1}$ The specialty initially struggled to achieve formal recognition. ${ }^{1}$ In 1968, the American College of Emergency Physicians (ACEP) was founded by several emergency physicians (EPs), with the establishment of the first EM residency training program quickly following in 1970 at the University of Cincinnati. ${ }^{1}$ By 1975, a total of 35 EM residencies had been established. ${ }^{1}$ In 1976, the American Board of Emergency Medicine (ABEM) was incorporated out of ACEP and worked with the University Association for Emergency Medicine (UAEM), the early academic EM organization, to develop a certification process for the specialty of EM. ${ }^{1}$ EM ultimately achieved formal recognition as the 23rd primary medical specialty by the American Board of Medical Specialties (ABMS) in 1979. ${ }^{1}$ In 1978, the formation of the American Osteopathic Board of Emergency Medicine (AOBEM) marked the emergence of osteopathic physicians within the field of EM. ${ }^{1}$

From the Department of Emergency Medicine, University of Michigan Medical School, Ann Arbor, MI.

Received June 4, 2019; revision received September 4, 2019; accepted September 30, 2019.

BJZ receives royalties from the book Anyone, Anything, Anytime - A History of Emergency Medicine, 2nd ed., published by the American College of Emergency Physicians. The other authors have no relevant financial information or potential conflicts to disclose.

Author contributions: BJZ developed the concept for the paper; MRCH drafted the manuscript and all authors contributed substantially to its revision; LRH additionally contributed to the statistical analysis and development of the graphs; and $\mathrm{MRCH}$ takes responsibility for the paper as a whole.

Supervising Editor: Sorabh Khandelwal.

Address for correspondence and reprints: Brian J. Zink, MD, e-mail: bzink@med.umich.edu

AEM EDUCATION AND TRAINING 2020;4:S13-S21. 
In 1995, a landmark conference sponsored by the Josiah Macy Jr. Foundation was held in Williamsburg, Virginia, to discuss the role of EM in the future of American medical care. ${ }^{2}$ The proceedings from the conference acknowledged the shortage of board-certified EPs at the time. ${ }^{2}$ Several resulting recommendations impacted the expansion of EM. The report recommended that government organizations maintain an adequate number of EM residency positions in the face of a changing health care landscape. ${ }^{2}$ The report also recommended that all medical schools establish appropriately staffed and supported academic emergency departments (EDs). ${ }^{2}$ An additional recommendation advised that every medical student acquire the knowledge and skills to care for ED patients through experiences supervised by qualified EPs. ${ }^{2}$ At the time of the report, fewer than $20 \%$ of U. S. medical schools offered required EM clerkships. ${ }^{2}$ A subsequent 1997 article evaluating the EM workforce predicted that supply of EPs would not equal demand until 2020 and called for the creation of additional EM residency programs to bridge the gap. ${ }^{3}$

Recent declarations of an overall impending physician shortage have also driven the expansion of EM. The American Association of Medical Colleges (AAMC) has predicted the shortage based on an aging physician workforce and rising demand by an aging patient population with increasing medical needs. ${ }^{4} \mathrm{~A}$ 2018 study anticipated a shortage of between 42,500 and 121,300 physicians in the U. S. by $2030 .{ }^{5}$ Concern over inadequate supply of future physicians has resulted in requests for additional funding to increase the number of trainee positions available for all specialties, including EM. ${ }^{5}$

As a result of this milieu, academic EM has expanded rapidly. The number of academic EDs has increased from 18 in 1989, to at least 115 accounted for in a 2018 AAMC faculty roster of department chairs. ${ }^{6,7}$ As of 2017, the percentage of U. S. allopathic medical schools requiring EM clerkships had increased to $56 \%{ }^{8}$ Similarly, the number of EM residency programs has increased from 82 in 1990 to 239 in $2018 .{ }^{9}$ One study found that nearly $75 \%$ of EM bound students come from medical schools with an affiliated EM residency program. ${ }^{10}$

The historical factors and trends that have resulted in the rapid expansion of EM have been applauded as addressing the feared physician shortage and improving patient access to unanticipated emergency care. ${ }^{11,12}$ However, the potential negative downstream effects of rapidly increasing the supply of EPs in the setting of potentially changing demand must also be considered.

\section{CURRENT AVAILABLE DATA AND PROJECTIONS}

\section{Assessing Supply}

The 2019 National Resident Matching Program (NRMP) Main Residency Match numbers were reviewed, including the number of first-year positions offered by EM and the fill rate. These numbers were compared to previous years to assess the rate of increase in the number of offered positions. Overall, the number of residency programs and trainee positions has rapidly increased for nearly all specialties, making the 2019 NRMP Main Residency Match the largest Match on record. ${ }^{13}$ EM specifically has also undergone a rapid expansion in the number of training programs and residency positions available and now represents $7.7 \%$ of available PGY-1 positions (Figures 1 and 2). ${ }^{13}$ Since 2014, the number of EM positions has increased dramatically by $702(36.6 \%) .{ }^{13}$ In the 2019 Match, EM offered 2,488 first-year positions, which is 210 more than 2018, which itself was 231 more than 2017. ${ }^{13}$ EM did fill all but 30 positions at 15 programs for a fill rate of $98.8 \%{ }^{13}$ The percentage filled by U. S. allopathic seniors, however, continued a downward trend and is now only $65.0 \%{ }^{14}$ The merger of the Accreditation Council for Graduate Medical Education (ACGME) and American Osteopathic Association (AOA) and the resultant movement of osteopathic students into the NRMP Main Match likely accounts for some of the decrease in fill rate by U. S. allopathic seniors. However, despite the increase in residency positions, the number of U.S. Seniors matching into EM has essentially plateaued over the past 3 years, raising potential concerns about saturation of the specialty among allopathic students. ${ }^{14}$

As the number of EM trainee positions has increased, so has the number of physicians who trained in an EM residency and subsequently completed board certification (ABEM and AOBEM diplomates). Data were obtained from both ABEM and AOBEM. Commensurate with the development of the specialty, the number of active ABEM diplomates has increased from 2,852 to 36,926 from 1984 to 2019 (e-mail communication, October 10, 2018). ${ }^{15}$ Combined with the current number of roughly 4,100 AOBEM-certified physicians (e-mail communication, October 20, 2018), this represents approximately 


\section{Cumulative Numbers of ACGME approved Emergency \\ Medicine Residency Programs by Year}

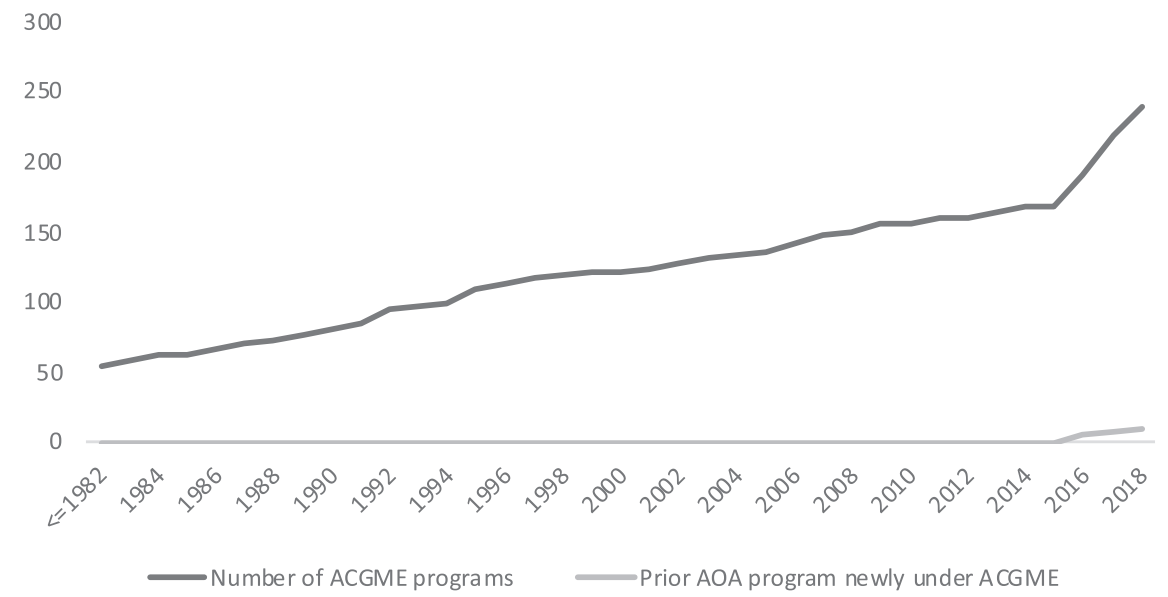

Figure 1. Illustration of cumulative numbers of ACGME-accredited EM programs showing the dramatic upward inflection in recent years. Existing programs moving from AOA to ACGME accreditation are shown separately as well as included in the cumulative total of ACGME programs. While the prior AOA programs influence the total, they represent only a minority of the newly approved programs. Publicly-available data was derived from the ACGME website reflecting year of initial ACGME accreditation decision by EM program. ${ }^{9}$

\section{Total EM NRMP positions}

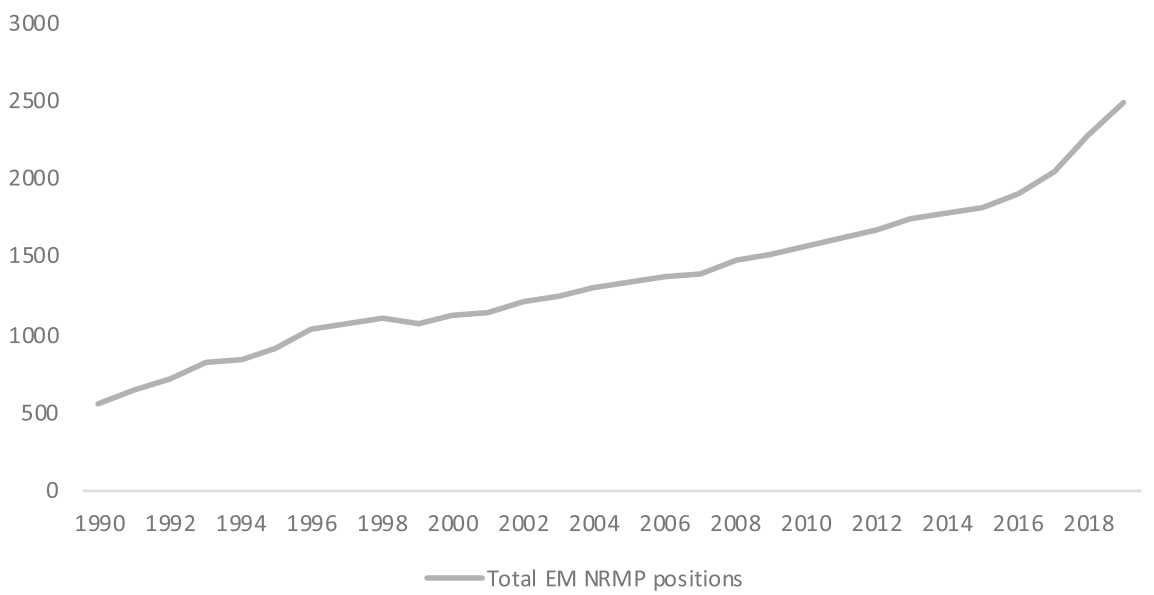

Figure 2. Number of EM positions available in the NRMP Match. Before 2011, numbers reflect total numbers of entering EM positions inclusive of PGY-1 and PGY-2 format programs. Publicly-available data was derived from NRMP reports. ${ }^{14,58}$

41,026 board-certified EPs, the vast majority of whom can be assumed to be in active clinical practice.

\section{Assessing Demand}

Projections of demand were assessed from previous reports in the literature. A 2016 article by Reiter et al. ${ }^{16}$ evaluating workforce trends projected that there can be enough ABEM/AOBEM-certified or eligible physicians to comprise the entire EP workforce by 2021, when accounting for both board-certified and board-eligible EPs anticipated to become board-certified. This projection was based on a $1.7 \%$ attrition rate estimated from a 2008 American Medical Association physician Masterfile. ${ }^{17}$ The projections from
Reiter et al. also correlate with a recent Health Resources and Services Administration (HRSA) article that anticipated a discrepancy between demand and supply, with demand for EPs projected to grow at $9 \%$ versus supply growing at 18\% between 2013 and $2025 .^{18}$ Of note, the HRSA data include self-reported EPs, some of whom may not be residency-trained or board-certified in EM. ${ }^{18}$

The demand for EPs will continue to be a complex and dynamic equation, with several evolving variables. For instance, the role of advanced practice providers (APPs) also affects EP supply and demand. Between 2013 and 2015, physician assistant supply in EM was projected to almost double during the same period 
that demand was expected to grow by only $9 \% .{ }^{18}$ The interplay of APP supply and demand and EP supply and demand may impact the EM workforce in ways that are difficult to predict. The phenomena of the commoditization of the profession, whereby tasks previously in the exclusive domain of the physician are now being forced to the lowest provider on the ladder competent to provide the service, will result in the need to redefine the role and utility of the EP relative to other health care professionals. ${ }^{19}$ Potential policy changes loosening supervision requirements and increasing independent practice of APPs may also reduce demand for EPs.

Additional factors with the potential to impact EP demand include an aging patient population and changes in physician utilization, health insurance coverage, and availability of primary care. The increase in freestanding emergency departments (FSEDs), which are located physically separate from a hospital, may increase demand as ACEP guidelines advise they be staffed by qualified EPs. ${ }^{20}$ As of 2017, between 550 and 600 FSEDs were reported, compared to only 80 in $2007 .^{21,22}$ FSEDs have been postulated to reduce the burden of crowding on traditional hospital-based EDs by drawing in lower-acuity patients and potentially improving access to care in rural areas where financial strain has reduced the number of critical-access hospitals. ${ }^{23}$ A recent analysis of the current state of FSEDs, however, suggests that they may cater to a more affluent patient population rather than address a lack of access to emergency care in underserved areas. $^{23}$ The role and impact of FSEDs within the larger system of emergency care thus remains uncertain and continues to evolve. Similarly, urgent care centers (UCCs), walk-in clinics focused on the delivery of medical care for minor illnesses and injuries, may also shunt patients with lower-acuity conditions away from traditional hospital-based EDs or FSEDs. ${ }^{24}$ One study estimated that $13.7 \%$ to $27.1 \%$ of all ED visits could take place at UCCs and retail clinics with an estimated potential cost savings of approximately $\$ 4.4$ billion annually. ${ }^{25}$ While some UCCs are staffed by EPs, the majority of these facilities are staffed by primary care physicians and APPs. ${ }^{24}$ The increase in UCCs could thus have variable effects on EP demand. Although EM attrition rates have been found to be relatively low and compare favorably to other specialties, changes in retirement age and practice hours per week may also occur as a new generation of EPs emerges, further impacting demand. ${ }^{17}$ Furthermore, the evolution of technology and development of new health care delivery modes and settings will increase the need for flexibility among physicians, including the ability to develop new skills and transition to new modes of practice. ${ }^{19}$ For instance, applications of telemedicine, defined as "the delivery of health care services at a distance, using information and communication technology," have rapidly expanded within EM. ${ }^{26,27}$ Telemedicine may impact workforce dynamics by effectively enhancing supply of EP expertise to small and rural hospitals. ${ }^{26}$ Additionally, the ACGME has questioned whether the traditional dichotomous model of generalist and specialist physicians is still the best way to approach planning for future medical education. ${ }^{19}$ The lines between who is competent and available to provide urgent or emergent care may blur, also affecting demand for EPs. ${ }^{19}$ More detailed explorations of the potential effects of such factors have been previously published. ${ }^{19,28,29}$

When assessing demand, it is also important to recognize that despite overall ED visits increasing by $40 \%$ over the past two decades, the number of EDs has simultaneously decreased by $11 \%{ }^{30}$ The demand for additional EPs may be attenuated by the trend toward ED closures at small hospitals, as visits from the closed EDs are usually consolidated into larger regional EDs in pursuit of economies of scale.

\section{IMPLICATIONS OF WORKFORCE PROJECTIONS}

Emergency medicine residencies in the United States are currently able to produce nearly 2,500 graduates per year with additional proposed residency programs in the pipeline for approval. The data cited above raise concerns that the EM workforce has the potential to soon reach a point of saturation. To better align the supply of EPs with future demand, the specialty must turn its attention to central workforce planning. Failing to do so could result in negative consequences on the EM workforce as have occurred in other parts of the world. For example, Australia has witnessed a similar explosion in popularity of EM in the absence of a central workforce planning system to provide feedback about supply and demand forces or to limit the number of trainees accepted into EM. ${ }^{31}$ The rapid growth in the number of EPs has even outstripped the rising number of ED visits. ${ }^{31}$ This has negatively impacted the workforce through the phenomenon of "exit block," where graduating trainees are unable to find 
jobs, as well as "zero-hours" contracts, where employed EPs are not guaranteed regular shifts. ${ }^{31} \mathrm{Sev}$ eral additional concerns have been raised, including dilution of training experiences and the graduation of trainees not well suited for EM. ${ }^{31}$

National planning for the EP workforce is required to provide a stable environment where medical students will be confident that they can find a job when they complete residency training. Grover et al. ${ }^{32}$ noted that a distinguishing feature of the physician workforce is that it relies partly on the collective result of individual physician's personal choices, including where and what to study and where to train and practice. Such factors can affect the workforce more profoundly than any government initiative. ${ }^{32}$

The specialty of anesthesiology offers a cautionary tale of how projections of oversupply can influence the career choices of medical students and physicians and massively impact the workforce. In the late 1980s and early 1990s, anesthesiology residency programs and positions greatly expanded, with the number of graduates quadrupling between 1984 and 1993. ${ }^{33}$ In 1994, the American Society of Anesthesiologists commissioned a study that projected a major oversupply of anesthesiologists in the coming decades. ${ }^{33,34}$ Simultaneously, the Council on Graduate Medical Education (COGME) advocated for efforts to increase the number of primary care physicians and limit the number of U.S. specialty physician trainees. ${ }^{33}$ A Wall Street Journal article and other media accounts highlighted difficulties experienced by graduating anesthesiology seeking jobs. ${ }^{35}$ In response to these factors, medical students rapidly moved away from anesthesiology as a specialty choice, with the number of U.S. medical school applicants to anesthesiology plummeting by $56 \%$ from 1995 to 2000 (from 1,784 to 787 ). ${ }^{34}$ Although the drop in applicants choosing anesthesiology was somewhat tempered by a large increase in international medical graduates matching into the specialty and growing numbers of certified nurse anesthetists, the resultant shortage of anesthesiologists persists today. ${ }^{33,34}$ Medical students' perceptions regarding job opportunities, income, and lifestyle factors are key drivers in their specialty selection. ${ }^{36}$ As the anesthesiology experience has shown, if those perceptions turn negative, the consequences can be rapid and enduring.

The rapid rise in the number of EM training positions has been more prevalent in certain areas of the country. For example, the state of Florida has demonstrated a particularly dramatic increase in the number of EM training positions, many offered by for-profit hospitals and large, corporate medical groups. ${ }^{37-39}$ Since 2013, the number of EM residency slots in Florida has increased by more than 200\%, compared to an only $20 \%$ increase in residency positions in all specialties between 2013 and 2017..$^{40-42}$ In 2018, an additional three EM residencies were approved by the Residency Review Committee for Emergency Medicine (RRC-EM) in Florida. ${ }^{43,44}$ A 2019 article in the Florida College of Emergency Physicians (FCEP) newsletter EM Pulse argued that there is little evidence to support that a critical shortage of EPs ever existed in Florida to justify this rapid expansion of EM training spots. ${ }^{44}$ The authors concluded that resources would be better shunted toward increasing access to primary care and that EM should not have been added to the list of "critical shortage specialties" on the 2013 Florida state legislative bill SB $1500 .^{44}$

Although the current data presented in this article do not support an impending overall shortage of EPs, rural areas do continue to see a shortage of EPs when compared to urban and suburban settings. ${ }^{45}$ A 2014 study evaluating Medicare data found that EPs comprise $63.9 \%$ of the emergency clinician workforce in urban counties versus only $44.8 \%$ of the workforce in rural counties where a greater proportion of nonemergency physicians and APPs practice. ${ }^{46}$ The study identified several factors driving this disparity, including location of residency programs, which tend to be more concentrated in urban areas. ${ }^{46}$ Additional factors reported by EM residency graduates as strongly influencing the decision to practice in urban versus rural environments include lifestyle, access to amenities/ recreation, ED volume/acuity, and family/spouse. ${ }^{47}$ Many of these factors are not easily amenable to change. Concomitant with the relative shortage of EPs in rural areas is a relative increase in ED visits to rural EDs demonstrated by a recent cross-sectional study of National Hospital Ambulatory Medical Care Survey data. ${ }^{48}$ While rural ED visits increased by more than $50 \%$ from 36.5 to 64.5 per 100 persons, urban ED visits stayed relatively stable, increasing from only 40.2 to 42.8 visits per 100 persons from 2005 to 2016 . $^{48}$ This suggests that there may not be a need to train additional EPs who are most likely to pursue jobs in urban ED environments, but rather a need to direct trainees toward rural ED settings. Rural training opportunities have the potential to significantly impact selection of rural practice settings as has been 
demonstrated in family medicine residents, including for those raised in urban areas. ${ }^{49,50}$ Although the shortage of rural training opportunities may be due to the perception that patient volume in rural EDs is inadequate for RRC-EM requirements, at least one study has found that patient volumes per physician were similar in rural and urban settings. ${ }^{51}$ An article by Handel et al. ${ }^{52}$ provides valuable recommendations for shunting trainees to rural areas, including creating financial incentives for residents to enter a rural EM practice through assistance with educational debt via government and/or hospital support, adjusting the RRC-EM guidelines to permit training experiences that offer a rural EM component and supporting innovative delivery of rural emergency care under supervision by EPs at academic medical centers via telemedicine. Leaders within EM will need to discuss and arrive at a consensus over whether educational initiatives will follow the recommendations set forth by Handel et al. to address the relative shortage of rural EPs or accept the greater proportion of nonemergency physicians and APPs filling the void in these areas.

In addition to affecting the ability of EM residency graduates to secure jobs upon the completion of training, an overabundance of EM residency positions could have wider-ranging implications for population health. The AAMC has projected a primary care (including family medicine, general internal medicine, general pediatrics, and geriatric medicine) physician shortage of 21,100 to 55,200 physicians by $2032 .^{53}$ Additionally, the AAMC continues to project especially significant shortages in surgical specialties and other specialties, such as psychiatry. ${ }^{53}$ One study evaluating influences on medical students' choice of EM found that internal medicine, general surgery, anesthesiology, family medicine, and pediatrics were in the top five most common specialties considered as either a student's first or second alternative. ${ }^{10}$ Individuals who may have otherwise chosen a specialty in need of additional manpower will have devoted time and resources to training in one that is already oversupplied. Additionally, educational debt continues to be a primary factor deterring college students from pursuing a career in medicine, particularly for underserved minorities. ${ }^{54}$ The AAMC estimated that the class of 2018 graduated with a median debt of $\$ 200,000$, up $4 \%$ from the previous year. ${ }^{55} \mathrm{EM}$ residency graduates unable to find a suitable job due to oversupply will face increased difficulty paying off student loans. Witnessing this phenomenon could further discourage young, bright minds of diverse backgrounds with the potential to advance medicine from applying to medical school.

History also demonstrates the cyclical nature of workforce projections, with the last century providing several examples of conflicting opinions on whether or not a shortage or oversupply is projected. ${ }^{32}$ The difficulty in formulating accurate projections is in part due to the many assumptions required to calculate them. As previously mentioned, our goal is to highlight potential challenges for the EM workforce and call for additional study to assess the implications of the rapid expansion of EM training programs as well as societal needs. A comprehensive, detailed workforce projection is beyond the scope of this work and excellent examples are available through the resources referenced above. $^{16,18}$ Despite the inherent difficulty in making accurate workforce projections, they should not be ignored. Workforce projections continue to have the potential to significantly influence public policy and medical student specialty selection, which can in turn affect workforce dynamics. Additional resources and efforts should target research that allows for increased accuracy of projections as well as more effective workforce monitoring and planning.

Several potential next steps exist to further explore and address the possible saturation of the EM workforce. National EM organizations must devote attention to this issue, examine workforce dynamics and consider regulating the expansion of EM residency positions. The American Academy of Emergency Medicine (AAEM) recently released a position statement expressing concern that the rapid growth of the EM workforce may result in saturation of the job market. ${ }^{56}$ National organizations should also convene an EM workforce summit involving representatives from the ACGME and the RRC-EM to discuss current issues and develop recommendations. Such decision making will require broad-based involvement from multiple specialty organizations representing the spectrum of stakeholders including leaders of departments and training programs, trainees and students, and regulatory organizations. A consensus-style conference hosted by one or more of the national societies could represent an opportunity for key stakeholders to develop a research and policy plan around EM workforce dynamics.

Additionally, no one particular organization currently assumes responsibility for monitoring EM workforce dynamics, and legal considerations may 
complicate strict formal regulation of such. A consensus-style conference could provide an opportunity to determine if and how a particular organization should regulate the number of existing EM residency programs. A natural candidate to consider for this role would be the ACGME, given its significant impact on the supply of EPs through the approval new programs. Up to this point, its mission has centered around determining whether a program meets quality standards for accreditation and not on whether the need for new programs exists. However, an oversupply of trainee positions could compromise the quality of training through competition for required experiences, and therefore the workforce dynamics of a specialty may need to be considered prior to the ACGME's approval of new programs as part of the mission to ensure high-quality training experiences.

Emergency medicine granting agencies such as the Emergency Medicine Foundation (EMF) and Society for Academic Emergency Medicine Foundation (SAEMF) should also consider developing specific grants to study the EM workforce. Beyond EM-specific organizations, collaboration with the AAMC's Workforce Studies Center to examine the EM workforce in detail would also represent a critical step, as the AAMC has continued to project shortages in a variety of specialties. ${ }^{57}$

\section{CONCLUSION}

The numbers and trends in the emergency medicine workforce demonstrate the continued robust growth of the specialty. Organizations and leaders in the field have applauded and encouraged this growth, but the data suggest that it is time to call for coordination and increased awareness to proactively maintain the vibrancy and health of emergency medicine workforce dynamics. The issue of workforce projections should be brought to the forefront of the agenda of national EM organizations. Central workforce planning may require regulating the number of residencies and expansion of programs to match future demand rather than risk exceeding it. Additionally, attention to enhancing rural emergency medicine opportunities and experiences for trainees may help redistribute emergency physicians to areas of existing shortage. Future studies are needed to better understand the factors that shape the EM workforce and to develop models that accurately and reliably predict the future workforce.

\section{REFERENCES}

1. Zink B. Anyone, Anything, Anytime - A History of Emergency Medicine. 2nd ed. Irving, TX: American College of Emergency Physicians, 2018.

2. Macy J Jr. The role of emergency medicine in the future of American medical care. Ann Emerg Med 1995;25:230-3.

3. Holliman CJ, Wuerz RC, Chapman DM, Hirshberg AJ. Workforce projections for emergency medicine: how many emergency physicians does the United States need? Acad Emerg Med. 1997;4:725-30.

4. Dall T, West T, Chakrabarti R, Iacobucci W. The Complexities of Physician Supply and Demand: Projections From 2013 to 2025. Washington, DC: Association of American Medical Colleges, 2015.

5. Dall T, West T, Chakrabarti R, Iacobucci W. 2018 Update: The Complexities of Physician Supply and Demand: Projections from 2014 to 2025. Washington, DC: Association of American Medical Colleges, 2018.

6. Heitz C, Hamilton G. The academic chair in emergency medicine: current demographics and survey results identifying the skills and characteristics desired for the role. Acad Emerg Med 2011;9:981-7.

7. AAMC Faculty Roster Table C: Department Chairs by Department, Sex, Race/ethnicity. 2018. Available at: https://www.aamc.org/download/495102/data/suppleme ntaltablec.pdf Accessed September 3, 2019.

8. Percentage of Medical Schools with Separate Required Clerkships by Discipline: Emergency Medicine. Available at: https://www.aamc.org/initiatives/cir/406450/05a.html. Accessed September 1, 2019.

9. ACGME Accredited Programs and Sponsoring Institutions Search and Reports. ACGME website searching for all emergency medicine programs and reviewing year of initial accreditation by program. Available at: https://apps.acgme. org/ads/Public/Programs/Search. Accessed November 15, 2018.

10. Ray JC, Hopson LR, Peterson W, et al. Choosing emergency medicine: influences on medical students' choice of emergency medicine. PLoS ONE 2018;13:e0196639.

11. Suter RE. Emergency medicine in the United States: a systemic review. World J Emerg Med 2012;3:5-10.

12. Anderson P, Hegedus A, Ohlen G, Holliman C, Williams D, Suter R. Worldwide growth of emergency medicine as a recognized medical specialty. Acad Emerg Med 2011;18: S22-3.

13. Thousands of Resident Physician Applicants Celebrate NRMP Match Results [Press Release]. Available at: http:// www.nrmp.org/one-nine-press-release-thousands-resident- 
physician-applicants-celebrate-nrmp-match-results/. Accessed April 29, 2019.

14. NRMP Advance Data Tables - 2019 Main Residency Match ${ }^{\circledR}$. Available at: https://mk0nrmpcikgb8jxyd19h.kin stacdn.com/wp-content/uploads/2019/03/Advance-DataTables-2019_WWW.pdf. Accessed April 29, 2019.

15. ABEM Exam and Certification Statistics. Available at: https://www.abem.org/public/resources/exam-certificationstatistics. Accessed April 29, 2019.

16. Reiter M, Wen LS, Allen BW. The emergency medicine workforce: profile and projections. J Emerg Med 2016;50:690-3.

17. Ginde AA, Sullivan AF, Camargo CA. Attrition from emergency medicine clinical practice in the United States. Ann Emerg Med 2010;56:166-71.

18. Health Resources and Services Administration. Health Workforce Projections: Physicians and Physician Assistants in Emergency Medicine. Available at: https://bhw.hrsa. gov/sites/default/files/bhw/health-workforce-analysis/resea $\mathrm{rch} /$ projections/fact-sheet-emergency-medicine.pdf.

Accessed December 19, 2018.

19. Nasca TJ, Thomas CW. Medicine in 2035: selected insights from ACGME's scenario planning. J Grad Med Educ 2015;7:139-42.

20. American College of Emergency Physicians (ACEP). Freestanding emergency departments. Policy statement. Ann Emerg Med 2014;64:562.

21. Sullivan AF, Bachireddy C, Steptoe AP, Oldfield J, Wilston T, Camargo CA Jr. A profile of freestanding emergency departments in the United States, 2007. J Emerg Med 2012;43:1175-80.

22. Stensland J, Gaumer Z, McClendon S.Using payment to ensure appropriate access to and use of hospital emergency department services. In: Report to the Congress: Medicare and the Health Care Delivery System. Available at: http://www.medpac.gov/docs/default-source/reports/ jun18_ch2_medpacreport_sec.pdf?sfvrsn=0. Accessed September 1, 2019.

23. Alexander AJ, Dark C. Freestanding emergency departments: what is their role in emergency care? Ann Emerg Med 2019;74:325-31.

24. Urgent care centers. Ann Emerg Med 2017;70:115-6.

25. Weinick R, Burns R, Mehrotra A.Many emergency department visits could be managed at urgent care centers and retail clinics. Health Aff (Millwood) 2010;29:1630-6.

26. Ward MM, Jaana M, Natafgi N. Systematic review of telemedicine applications in emergency rooms. Int J Med Inform 2015;84:601-16.

27. Sood S, Mbarika V, Jugoo S, et al. What is telemedicine? A collection of 104 peer-reviewed perspectives and theoretical underpinnings. Telemed J E Health 2007;13:573-90.

28. Holt KD, Miller RS, Philibert I, Nasca TJ. Patterns of change in ACGME-accredited residency programs and positions: implication for the adequacy of GME positions and supply of physicians in the United States. J Grad Med Educ 2014;6:399-403.

29. Rockey PH, Rieselbach RE, Neuhausen K, et al. States can transform their health care workforce. J Grad Med Educ 2014;6:805-8.

30. American Hospital Association. TrendWatch Chartbook 2015: Emergency Department Visits, Emergency Department Visits per 1,000 Persons, and Number of Emergency Departments, 1993-2013. 2015. Available at: http://truec ostofhealthcare.org/wp-content/uploads/2018/06/AHASta tsBook2015.pdf. Accessed March 29, 2019.

31. Rosie C. Is Australasia producing too many emergency physicians? Yes. Emerg Med Australas 2015;27:599-600.

32. Grover A, Orlowski JM, Erikson CE. The nation's physician workforce and future challenges. Am J Med Sci 2016;351:11-19.

33. Reves JG, Rogers MC, Smith LR. Resident workforce in a time of U.S. health-care system transition. Anesthesiology 1996;84:700-11.

34. Schubert A, Eckhout G, Cooperider T, Kuhel A. Evidence of a current and lasting national anesthesia personnel shortfall: scope and implications. Mayo Clin Proc 2001; 76:995-1010.

35. Anders G.Numb and number: once a hot specialty, anesthesiology cools as insurers scale back. Wall Street Journal. March 17, 1995. Available at: https://www.apnews.com/Off 8af6e9ab84b8a994aa4f123c6dc74. Accessed December 19, 2018.

36. Boyd JS, Clyne B, Reinert SE, Zink BJ. Emergency medicine career choice: a profile of factors and influences from the Association of American Medical Colleges (AAMC) graduation questionnaires. Acad Emerg Med 2009;16:544-9.

37. Stein L.HCA hospitals to add hundreds of medical residencies in Tampa Bay. Tampa Bay Times. November 14, 2012. Available at: http://www.tampabay.com/news/hea lth/hca-hospitals-to-add-hundreds-of-medical-residencies-intampa-bay/1261497. Accessed April 29, 2019.

38. Miller NS.UCF and HCA partner to bring 550 new residency slot. Orlando Sentinel. October 12, 2015. Available at: https://www.orlandosentinel.com/health/os-ucf-hca-ne w-residencies-20151012-post.html. Accessed April 29, 2019.

39. Cook T. After the match: corporations rush in to fill MD shortage. Emerg Med News 2017;39:32.

40. Safety Net Hospital Alliance of Florida; Teaching Hospital Council of Florida; Teaching Hospital Council of Florida. Training Tomorrow's Doctors: Graduate Medical Education in Florida 2016 Annual Report. Available at: http://mediad.publicbroadcasting.net/p/wusf/files/201610/ gme_2016_annual_report_final.pdf. Accessed April 12, 2019. 
41. NRMP Main Residency Match: Match Rates by Specialty and State. Available at: https://mk0nrmpcikgb8jxyd19h. kinstacdn.com/wp-content/uploads/2014/06/Main-MatchResults-by-State-and-Specialty-2013.pdf. Accessed April 12, 2019.

42. NRMP Main Residency Match: Match Rates by Specialty and State. Available at: https://mk0nrmpcikgb8jxyd19h. kinstacdn.com/wp-content/uploads/2017/06/Main-MatchResults-by-State-and-Specialty-2017.pdf. Accessed April 12, 2019.

43. NRMP Main Residency Match: Match Rates by Specialty and State. Available at: http://www.nrmp.org/wp-content/ uploads/2018/04/Main-Match-Result-by-State-and-Specia 1ty-2018.pdf. Accessed December 19, 2019.

44. Orban D, Langland B. The lack of evidence of an emergency physician workforce shortage in Florida. Florida College of Emergency Physicians EM Pulse 2019;25:2627. Available at: https://issuu.com/floridacollegeofemerge ncyphysicians/docs/empulse_winter_2019_final/26. Accessed March 26, 2019.

45. Cheney C.ER staffing split along urban-rural divide. Health Leaders Media. Available at: https://www.health leadersmedia.com/clinical-care/er-staffing-split-along-urbanrural-divide-0. Accessed March 28, 2019.

46. Hall MK, Burns K, Carius M, Erickson M, Hall J, Venkatesh A. State of the national emergency department workforce: who provides care where? Ann Emerg Med 2018;72:302-7.

47. Helland LC, Westfall JM, Camargo CA, Rogers J, Ginde A. Motivations and barriers for recruitment of new emergency medicine residency graduates to rural emergency departments. Ann Emerg Med 2010;56:668-73.

48. Greenwood-Ericksen MB, Kocher K. Trends in emergency department use by rural and urban populations in the United States. JAMA Netw Open 2019;2:e191919.
49. Chan BT, Degani N, Crichton T, et al. Factors influencing family physicians to enter rural practice: does rural or urban background make a difference? Can Fam Physician 2005;51:1246-7.

50. Brooks RG, Mardon R, Clawson A. The rural physician workforce in Florida: a survey of US- and foreign-born primary care physicians. J Rural Health 2003;19:484-91.

51. Reames J, Handel DA, Al-Assaf A, Hedges JR. Rural emergency medicine: patient volume and training opportunities. J Emerg Med 2009;37:172-6.

52. Handel DA, Hedges JR; SAEM IOM Task Force. Improving rural access to emergency physicians. Acad Emerg Med 2007;14:562-5.

53. Association of American Medical Colleges. 2019 Update: The Complexities of Physician Supply and Demand: Projections From 2017-2032. April 2019. Available at https://aamc-black.global.ssl.fastly.net/production/media/ filer_public/31/13/3113ee5c-a038-4c16-89af-294a69826650/ 2019_update_-_the_complexities_of_physician_supply_and_ demand__projections_from_2017-2032.pdf. Accessed September 1, 2019.

54. Jolly P. Medical school tuition and young physicians' indebtedness. Health Aff (Millwood) 2005;24:527-35.

55. AAMC Medical Student Education: Debt, Costs and Loan Repayment Fact Card. Available at: https://store.aa mc.org/downloadable/download/sample/sample_id/240/. Accessed September 1, 2019.

56. AAEM Position Statement on the Emergency Medicine Workforce. Available at: https://www.aaem.org/resources/ statements/position/em-workforce. Accessed April 18, 2019.

57. AAMC Workforce Studies. Available at: https://www.aa mc.org/data/workforce. Accessed April 24, 2019.

58. Results and Data: NRMP Main Residency Match. Available at: http://www.nrmp.org/report-archives/. Data from years 1984-2018. Accessed November 15, 2018. 